Article

\title{
The Mediating Effect of Organizational Citizenship Behavior in the Relationship between Transformational Leadership and Corporate Social Responsibility Practices: Middle Eastern Example/Jordan
}

\author{
Khaled Alshihabat*(D) and Tarik Atan (D) \\ Department of Business Administration, Faculty of Economic and Administrative Sciences, \\ Cyprus International University, Nicosia 99258, Cyprus; tatan@ciu.edu.tr \\ * Correspondence: khalid.shihabat@yahoo.com
}

Received: 12 April 2020; Accepted: 20 May 2020; Published: 22 May 2020

\begin{abstract}
The main objective of this study was to investigate the mediating effect of organizational citizenship behavior (OCB) in the relationship between transformational leadership (TLS) and corporate social responsibility practices (CSR). Another objective was to present adequate properties regarding the reliability of the scores, and evidence of the validity of the internal structure of the measurement instrument. Structure equation modeling (SEM) was used to analyze the data, which was randomly collected from 392 participants from the universities of Jordan. The overall assessment of the model was accepted and TLS was found to indirectly and significantly impact CSR practices through OCB, where the direct effect was significant, though lower than the indirect impact. This means that TLS is a good predictor of CSR practices, especially with the mediation of OCB. One of the implications of this finding is that leaders should promote OCB among their employees, as this will be reflected in their CSR practices, which is one of the requirements of sustainability. The originality of this research lies in it being the first to explore the indirect effect of TLS on CSR practices through OCB.
\end{abstract}

Keywords: sustainability; transformational leadership style (TLS); corporate social responsibility (CSR); organizational citizenship behavior (OCB); Jordan universities

\section{Introduction}

Universities may not be excluded from companies of high economic force. They cannot be underestimated, especially in terms of their production. Indeed, this is because universities are centers of knowledge generation and sharing and play a very important role in solving the world's problems and ensuring a sustainable tomorrow by providing awareness and new knowledge. Given this power, it is important to take a hard look at whether these corporate giants are indeed upholding their end of the social compact. The failure to study the impact of these companies on society represents a great risk, such as severe environmental degradation. Nevertheless, corporations have promised significant job creation and an overall improvement in social welfare [1]. In fact, this might be needed to achieve a positive impact on sustainability issues, which will lead to long-term benefits for companies and society. Therefore, there is a need to move companies toward better social and environmental performance. This means being prepared and able to face the most difficult environmental challenges society faces, such as climate change, habitat destruction, and water scarcity. This is where the role of corporate social responsibility (CSR) should be considered essential. 
Ogbonna and Harris [2] showed that the interaction between organizational citizenship behavior (OCB) and transformational leadership style (TLS) affects the level of corporate performance. More importantly, this is due to the fact that corporate sustainability is mortgaged by TLS and $\mathrm{OCB}$, which are linked to inherent human values [3], meaning that the needs of the organization and all stakeholders in terms of economic, social, and environmental justice can be met-this is called CSR. That is, there is a need to integrate human values and institutions through CSR to achieve overall sustainability. Eventually, these practices are associated with OCB in terms of social identity theory [4], in which the worker identifies themselves through their company.

Meanwhile, it has become clear that corporate leadership needs to spark the drive for a positive impact on the environment, which will also have long-term benefits for companies and society [3]. Companies need to move toward better social and environmental performance. This means being prepared and able to face the most difficult environmental challenges society faces, such as climate change, habitat destruction, and water scarcity [5]. In fact, this is where the role of CSR becomes synonymous with corporate citizenship and corporate sustainability [6]. CSR is a self-organizing model to be socially responsible [7]. This means that the company operates in a sustainable manner within itself, society, and the environment [6]. Sustainability initiatives give hope for continued existence and life. Central to this is the integration of institutions and values. However, many institutional sustainability approaches relate to interaction and compliance, rather than creative competency to meet the needs and demands of stakeholders [3]. Paying more attention to CSR practices and OCB is essential.

OCB improves sustainability performance for three main reasons: first, it builds the capabilities and values to effectively overcome internal and external threats facing a company, and secondly, it significantly enhances long-term performance, growth, and profitability. Thirdly, and most importantly for our study, it has a role in the development of CSR [3]. The importance of CSR lies in the fact that resources cannot be consumed without taking into account their consumption, as resources are not endless, which means that companies, society, and the environment are interconnected [5]. This means that focusing on one aspect of sustainability, such as the economy, is futile and harmful to the survival of the companies themselves, as it is necessary to combine both institutions and human values. That is why ISO 26000 was issued to help companies implement CSR [8]. It provides specific guidance, because the nature of CSR still focuses on quantity more than quality. These standards target all types of organizations, regardless of their activity, size, or location. Nevertheless, there is international consensus regarding these standards, which is due to the fact that many key stakeholders from all over the world contributed to them.

According to Shephard and Guiney [9], this necessarily applies to university institutions around the world, including universities in Jordan. Such institutions are always striving for competence, growth, and excellence to cope with the dynamic pace of changes. In fact, according to Nejati et al. [10], the world-leading universities are committed to social responsibility, which in the end generates economic, social, and environmental benefits (i.e., to contribute to the three pillars of sustainable development defined by the United Nations Conference on Environment and Development in 1992) [11]. In addition, organizations such as companies or universities are frequently responsible for severe environmental degradation [12].

It further applies to universities because higher education institutions can cause "significant environmental impacts" [13]. This is due to their large size, expressive movement of people and vehicles, high consumption of materials, and strong development of complex activities; from many perspectives, they may even be considered "small towns" [14]. More importantly, universities are centers of knowledge generation and sharing. They play a very important role in solving the world's problems and ensuring a sustainable tomorrow by providing awareness and new knowledge. Many organizational decision-makers were once students in universities, and it is important to know how universities regard CSR. This necessarily means that universities should be responsible toward society and their stakeholders. In fact, to strengthen this social contract, which allows such organizations to continue 
their operations [15], they need to be socially responsible. Fortunately, as discussed by Leal [16], there is a high level of acceptance regarding the importance of pursuing sustainability-including its economic, social, and environmental dimensions.

However, while some literature claims a strong relationship between TLS and OCB, OCB and CSR, and TLS and CSR [17], there is still a gap in the study of the mediation effect of OCB between TLS and CSR, as none of the previous studies have addressed this issue.

\subsection{Statement of the Problem}

In Jordan, the growth of the educational industry has been impressive in the past two decades. Jordan has 29 universities that collectively generate thousands of graduates each year, from mixed cultures [18], in many specialties, including engineering and medicine, for the local market and for neighbouring countries, especially the Gulf countries [19]. This means that the prosperity of the universities sector in Jordan and its impacts on sustainability issues merit closer attention. This might potentially impact the sector's performance in general, as its performance is the outcome of the interaction of many factors, among which is the interaction between leadership style, OCB and CSR in particular, which is the main focus of this study.

However, as recent studies have confirmed that TLS and OCB have become a problem that significantly hinders the sustainability of higher education development and performance, and confirmed that OCB can allow the enterprise to meet multiple stakeholders' needs and demands around sustainability, the researchers chose to investigate the impact of leadership in CSR through OCB mediation.

In this regard, as TLS has been highlighted as a critical determinant of OCB [2], and OCB as a determinant of CSR $[3,4]$, there remains a limited understanding of how these major factors interact. Therefore, the aim of this paper is to investigate this gap; assuming that although TLS may directly impact CSR, the indirect impact of TLS on CSR would be much greater and more significant when mediated by OCB [17].

Nevertheless, the significance of this study comes from the fact that despite the existing research conducted on the interaction between TLS, OCB, and CSR, none has focused on investigating the mediating effect of OCB between TLS and CSR. For this reason, this study investigated the impact of TLS on CSR through the mediation of OCB. Moreover, the significance of this research lies in being new in the Jordanian context, offering a deeper insight and understanding into the relationship between OCB, TLS, and CSR. Most of the existing studies that have been conducted in the particular context of universities in Jordan are mostly descriptive in nature. More importantly, this study attempts to build a valid model, with an empirical proof that fits the Jordanian context, that can be used to measure the direct and indirect impact of TLS on CSR through the mediation of OCB.

\subsection{Literature Review}

\subsubsection{Leadership and Leadership Styles}

Leadership is considered a basic concept that implies influence over followers, and is involved in the development of organizational theory in management. Leadership is mostly conceptualized within the behavioral domains [20]. According to Goleman et al. [21], there has been an increased interest over time in the aspects related to practices of leadership from a quality point of view. Leaders are interested in achieving success through satisfying the goals and objectives of their organizations. In addition, people in general, and leaders or managers in particular, tend to possess leadership skills inherently and then learn certain leadership characteristics and skills to manage with challenges that may arise in various situations throughout life, assisting them in successfully overcoming such challenges and obstacles. Thus, individuals or organizations that do not have well-developed, skilled leaders may face insurmountable challenges. 
Taking into consideration the widely accepted axiom that leaders are not exclusively "born leaders" but are, rather, most often "grown" or "developed", researchers have worked to develop instruments and tools to measure styles of leadership that involve certain behavioral traits associated with good leadership. According to Yusra et al. [22], the following are the styles of leadership one adopts: autocratic leadership (the boss), democratic leadership (all-inclusive), laissez-faire or free rein leadership (chilled-out), bureaucratic leadership, charismatic leadership (motivational), paternalistic leadership (family-oriented), transactional leadership, servant leadership, entrepreneurship leadership styles, the coaching style, cross-cultural/diverse leadership, the leader exchange style, situational leadership, strategic leadership, facilitative leadership, the participative leadership style, the visionary leadership style, and transformational leadership. However, people as leaders adopt different styles for different kinds of jobs according to the circumstances. In our study, the focus will be on TLS, as its primary focus is to make change happen in ourselves, others, groups, and organizations, which fits our goals. Therefore, the framework that is at the base of this research is the transformational leadership theory. According to Yusra et al. [22], this theory encourages, motivates, and supports employers, often involves recognizing and rewarding people for their good work, and inspires their team to work together towards a common target.

In TLS, the leader identifies changes that are needed and creates a vision with commitment. Transformational leadership consists of many components. Pillai et al. [23] studied four of these components: The first component, charisma (idealized influence), is defined as "followers trust and identify emotionally with the leader". The second component, inspiring motivation, means that followers receive emotional symbols and appeals to $\mathrm{w}$ focus on achieving goals, and having high expectations. The third component, intellectual stimulation, refers to "promoting the ability to question the ways of doing things". The last factor, individualized consideration, means that "tasks provide employees with learning opportunities". Wagude et al. [24] added in their study the concept of idealized behavior, which is defined as the need for change and a vision and to mobilize employees to effectively perform beyond expectations. Moreover, Castillo et al. [25] conducted a study that focused on the associations between coaches' value priorities and their transformational leadership behaviors, exploring the potential mediation versus moderation effect of two alternative variables in this relationship: perceived club pressure or an autonomy supportive environment. The study concluded and highlighted the importance of identifying the value base on which to develop transformational leadership programs in order to enhance positive experiences in the sport domain.

\subsubsection{Organizational Citizenship Behavior (OCB)}

OCB is recognized as an individual's behavior that collectively and effectively increases the performance of any particular organization. However, although the ethical impact of OCB in organizations is known, its causal influence on employees has not been fully investigated [26]. In their study, Cohen [27] expressed their opinions about the importance of OCB in organizations, and emphasized the role of OCB in the effective performance of organizations.

According to Igor et al. and Khan [28,29], most scholars define OCB as a latent variable consisting of five components: conscientiousness, civic virtue, courtesy, sportsmanship, and altruism. Altruism refers to the readiness of workers to help their colleagues in their tasks in an organization. Courtesy is the respect expressed by employees to colleagues. Sportsmanship refers to the readiness of employees to accept less optimal conditions and the presence of a positive attitude, without making complaints. Civic virtue refers to the improvement of a company. Conscientiousness is behavior that is not required by the organization.

OCB can be argued to include activities that are extra and above an employee's formal job requirements [30]. Smith et al. and Yildiz [31,32] emphasized that OCB does not depend on incentives. The study by Akinbode [33] did not show a positive association between some factors among participants, including age, gender, tenure, management level organization, demographic variables, and OCB. For example, Okediji et al. [34] did not show any role for gender in OCB. Kim [35] showed 
that OCB does not depend on financial returns, but on the perception of employees of their personal values in their organization. However, other studies have showed that females are more likely to exhibit OCB than males, and OCB increases with age. Moreover, Broucek [36] evaluated the reasons behind student $\mathrm{OCB}$, and found warmth to be the strongest predictor of OCB.

Nusair et al. [37] provided a good understanding of how TLS is related to innovative behavior. They demonstrated that TLS is a good predictor of innovative behavior. In addition, they found that the place of work significantly impacts attitudes and innovative behavior. Moreover, Tareq [38], in his research into three banks operating in Jordan, considered the role of TLS in terms of its four components-inspirational motivation, individual consideration, idealized influence, and intellectual stimulation-and their impact on organizational performance. The results showed that leaders need to focus on inspirational motivation, individual consideration, and intellectual stimulation to improve the results of organizational performance, while idealized influence was found not to contribute significantly to this outcome. Moreover, Akif and Sahar [39] investigated the impact of three leadership styles of academic staff on modifying students' behavior in Jordanian universities. They showed that the academic staff using a democratic style most effectively modified students' behavior.

Alsheikh and Sobihah [40] emphasized how organizational commitment, leadership style, and organizational culture influence $\mathrm{OCB}$, with the moderating role of job satisfaction in the relationship. Moreover, Abd and Cohen [41] examined the interaction between values, social exchange variables, and OCB and in-role performance. The results showed that openness to change was related to altruistic $\mathrm{OCB}$, while self-transcendence was related to in-role performance. More importantly, they showed that employees' behavior can be better understood through these values and variables in the workplace.

\subsubsection{Corporate Social Responsibility (CSR)}

The literature includes many studies related to different aspects of CSR in conjunction with leadership style and OCB. Nejati et al. [10] questioned whether world-leading universities are concerned about CSR and, if they are, to what extent they are committed to their social responsibilities. The findings showed that world-leading universities are committed to their social responsibility, and they provide sufficient information on most of the core areas of CSR. Oo et al. [42] examined organizational pride as the underlying psychological mechanism explaining the relationship between CSR perception and OCB. It was found that organizational pride mediated the CSR perception-OCB relationship. In addition, collectivism orientation strengthens the CSR-pride relationship, while person-organization fit strengthens the OCB-pride relationship. Cingöz et al. [43] examined the relationships among CSR, $\mathrm{OCB}$, and ethical leadership. The findings indicated a significant and positive relationship between CSR and ethical leadership. However, no significant relationship was found either between OCB and CSR, or OCB and ethical leadership. Gao and He [44] proposed a trickle-down model and examined the mediating role of supervisors' ethical leadership and the moderating role of perceived organizational distributive justice in the CSR-OCB relationship. Their empirical findings demonstrated that CSR had a positive effect on employee $\mathrm{OCB}$, as mediated by supervisors' ethical leadership. In addition, this mediation effect was found to be moderated by perceived organizational distributive justice, such that the mediation relationship was stronger when perceived organizational distributive justice was lower than when it was higher. Wang [45] proposed and tested a sequential mediation model in which CSR promoted organizational prestige. They found that organizational prestige increases employees' collective organizational identification and, consequently, enhances their collective OCB at the firm level. Mohammad and Nik [46] investigated the implementation of CSR programs and their impact on OCB among employees. It was found that employee behavior OCB is also dependent on the organization's commitments toward non-business social agendas, and that the commitment seems to correlate positively with employees' own altruistic behaviors among themselves. Ong et al. [47] developed a CSR sensitivity framework that explains how task significance, a micro-level job characteristic, can sensitize employees to their organizations' macro-level CSR efforts, thereby strengthening the association between CSR and OCB. It was found that CSR and task significance interact to predict OCB, where CSR 
is more positively associated with OCB among employees who report higher task significance than among those who report lower task significance. Iqbal et al. [48] examined the effect of authentic leadership on OCB, as well as examining the mediating mechanism of CSR on the aforementioned relationship. It was found that authentic leadership positively predicts OCB. Furthermore, it was found that CSR positively mediates the relationship between authentic leadership and OCB.

\subsection{Development of the Hypotheses}

The literature indicates a positive correlation between different types of leadership, such as ethical leadership, transformational leadership, and transactional leadership, and CSR [49,50]. In addition, the current literature shows a positive and significant correlation between TLS and OCB [51-54]. However, the psychological mechanisms underlying such relationships are still unclear, as there is the potential for a missing link with some mediating effects. However, some studies have emerged to investigate certain mediation roles, such as that of Iqbal et al. [48], who studied the impact of authentic leadership on OCB and the mediating role of CSR. However, studies related to the link between TLS and CSR with the mediating effect of OCB are scarce. Based on the above literature, it is suggested that TLS plays a vital role in influencing CSR practices through the mediation of OCB. Therefore, we hypothesized that:

Hypothesis 1 (H1): The measurement instruments present adequate properties regarding the reliability of the scores and evidence of the validity of the internal structure;

Hypothesis 2 (H2): TLS directly impacts CSR practices through OCB;

Hypothesis 3 (H3): TLS indirectly impacts CSR practices through OCB.

\section{Materials and Method}

\subsection{Tools}

From the above insights on TLS, OCB, and CSR and their contexts, together with those of many other authors, this research focused on five key aspects of TLS, five key aspects of OCB, and four key aspect of CSR. The five key aspects of TLS were inspirational motivation (INSMOT), idealized behaviors (IDBEH), idealized influence (IDINF), intellectual stimulation (INTSTIM), and individual consideration (INDCON). The five key aspects of OCB were conscientiousness (Cons), civic virtue (CivVir), sportsmanship (Sport), courtesy (Cour), and altruism (Altru). The four key items of CSR practices included environmental, ethical, and stakeholder-relation CSR practices, which are CSR Practice1, CSR Practice2, CSR Practice3, and CSR Practice4. With regards to OCB, the researchers adopted the five aspects of TLS, which are composed of 20 items or questions, from the Multifactor Leadership Questionnaire [55], whereas the other five aspects of OCB, which are composed of 24 items or questions, were adopted from Podsakoff et al.'s work [56] after being subjected to validation. Appendix A presents the five aspects of TLS with its items or questions, while Appendix B presents the five aspects of OCB with its items or questions. Appendix $C$ presents the four items of CSR practices. Thus, our study was based on and limited to the above mentioned 14 aspects.

\subsection{Particiants and Data Gathering}

Data were collected from a total of 418 self-administered questionnaires. These questionnaires were approved by the ethical review board of the authors' university. All questionnaires were distributed by the researcher randomly to employees in three out of five governmental universities, and two other private universities out of 26 private universities in Jordan. Alongside the demographic questions, the questionnaire covered the 48 questions (items) of TLS, CSR, and OCB, using a five-point Likert scale where $5=$ Not at All, $4=$ Once in a While, $3=$ Sometimes, $2=$ Fairly Often, and $1=$ Frequently, If Not 
Always. Only 392 questionnaires were returned as valid after data screening, which represents $94 \%$ of the distributed questionnaires.

\subsection{Data Analysis}

The data were input into IBM SPSS AMOS (23) software for analysis, and structural equation modeling, SEM (CB-SEM), was employed. Confirmatory factor analysis (CFA) was used for model fit and to assess the validity and reliability of the data, while path analysis was used to estimate the impact of TLS on CSR with the mediation of OCB, with the Maximum Likelihood (ML) estimation method. CFA is the best-known statistical analysis for testing a hypothesized factor structure $[57,58]$. This method was recommended and used by $[42,44,45,47,50-53]$. Accordingly, the model fitness was evaluated using several criteria, including the Chi-square, Goodness-of-Fit Index (GFI), Adjusted Goodness-of-Fit Index (AGFI), Comparative Fit Index (CFI), and Root Mean Square Error of Approximation (RMSEA) [57,58]. The first regression path in each measurement component was fixed at (1) for model identification purposes. All items of the three constructs were initially incorporated into the model testing for first-order confirmatory factor analysis, and the remaining were incorporated in the second-order confirmatory factor analysis. Items were evaluated using item loading and error variance estimates; evidence of items needing to cross-load on more than one component factor was indicated by large modification indices [57].

\subsection{Demographic Characteristics of Study Participants}

Gender, age, type of work, income in Jordanian Dinar (JD), and type of university were considered in this study as the demographic variables. Table 1 characterizes comparative demographics of the study participants. The mean age for employees in universities was 41.5 years; $51.0 \%$ were less than 40 years and $49.0 \%$ were 40 years and older. Among the participants, $61.5 \%$ were male and $38.5 \%$ were female. Bachelor and doctorate levels of education dominated the sample, with $27.8 \%$ and $25.5 \%$, respectively. In addition, academic staff members were the largest group, at $38.5 \%$. Years of experience varied; $12.0 \%$ of the participants had 1-5 years of experience, $29.6 \%$ 6-10 years, and $58.4 \% 11$ years or more. Most participants earned an income of 500 and less (40.1\%), while 32.7\% earned 501-1000 JD, as shown in Table 1.

Table 1. Demographic characteristics of study participants.

\begin{tabular}{lcc}
\hline \multicolumn{1}{c}{ Group } & Frequency & Percentage \% \\
\hline Gender & 241 & \\
Male & 151 & 31.5 \\
Female & & \\
\hline Age & 200 & 51.0 \\
Less than 40 Years & 192 & 49.0 \\
40 Years and Older & & \\
Level of Education & 59 & 15.1 \\
High School and Less & 53 & 13.5 \\
Diploma & 109 & 27.8 \\
Bachelor & 71 & 18.1 \\
Master & 100 & 25.5 \\
Doctorate & & \\
\hline Type of Work & 105 & 26.8 \\
Services & 62 & 15.8 \\
Technicians & 151 & 38.5 \\
Academic & 74 & 18.9 \\
Management & &
\end{tabular}


Table 1. Cont.

\begin{tabular}{lcc}
\hline \multicolumn{1}{c}{ Group } & Frequency & Percentage $\%$ \\
\hline Years of Experience & & \\
1-5 Years & 47 & 12.0 \\
6-10 Years & 116 & 29.6 \\
11 Years and More & 229 & 58.4 \\
\hline Income in JD & & \\
500 and Less & 157 & 40.1 \\
501-1000 & 128 & 32.7 \\
1001-1500 & 69 & 17.6 \\
1501 and More & 38 & 9.7 \\
\hline Type of University & & \\
Public & 188 & 48.0 \\
Private & 204 & 52.0 \\
\hline
\end{tabular}

\section{Results}

\subsection{Data Analysis: First-Order Confirmatory Factor Analysis}

Table 2 shows the standardized regression weights for all the items and their components before any modification, where the first regression path in each measurement component was fixed at (1) for model identification purposes. Table 2 shows the initial factor loadings for all items, which ranged from -0.098 for IDBEH1 to 0.953 for CivVir.

Table 3 shows the recommended and acceptable values or The goodness of fit (GOF) Indices of Measurement Model, which otherwise was considered as a bad fit for the model. The initial measurements without any modification were: Chi-square $=2814.393$, Chi-square/df(the number of degrees of freedom) $=2.743, \mathrm{df}=1026, \mathrm{GFI}($ goodness of fit index $)=0.758$, AGFI (adjusted goodness of fit index $)=0.722$, CFI(The comparative fit index $)=0.806$, TLI (The Tucker-Lewis coefficient) $=0.787$, $\operatorname{IFI}($ the incremental fit index $)=0.808, \operatorname{RMSEA}($ the root mean square error of approximation $)=0.067$. To improve the fitness of this model, many items were eliminated using item loadings with a cut-off of 0.5 weight [59], the error variance estimate and items cross-load on more than one component factor [57]. Thus, no items were eliminated from IDINF; one item was eliminated from IDBEH; one item was eliminated from INSMOT; two items were eliminated from INTSTIM; and two items were eliminated from INDCON, such that only 14 items remained from 20 items in the final construct of TLS. On the other hand, three items were eliminated from INDCON; two items were eliminated from Sport; two items were eliminated from CivVir; three items were eliminated from Cour; and none were eliminated from Altru, giving 14 items from 24 items for the final construct of OCB. In addition, one item was eliminated from CSR practices, giving three items. Table 2 shows the modified first-order loadings, which ranged between 0.508 for CSR Practice1 and 0.965 for CivVir3.

Thus, after deleting the aforementioned 17 low loading items, the measurement indices gave more acceptable GOF values: Chi-square $=833.202$, Chi-square $/ \mathrm{df}=2.193, \mathrm{df}=380.000, \mathrm{GFI}=0.882$, $\mathrm{AGFI}=0.846, \mathrm{CFI}=0.934, \mathrm{TLI}=0.920, \mathrm{IFI}=0.935, \mathrm{RMSEA}=0.055$.

Comparing these values before and after modification with the recommended values in Table 3 showed that new modified values were more acceptable for further analysis, which means that these results indicate that the new model fit better to the sample data than did the original model. 
Table 2. Standardized regression weights: (initial and modified values).

\begin{tabular}{|c|c|c|c|}
\hline \multicolumn{2}{|c|}{ Items $<-$ Component Factors } & \multirow{2}{*}{$\begin{array}{c}\text { Initial Factor Loadings } \\
0.604\end{array}$} & \multirow{2}{*}{$\begin{array}{c}\text { Modified First-Order Loadings } \\
0.601\end{array}$} \\
\hline IDBEH4 & \multirow{4}{*}{ IDBEH } & & \\
\hline IDBEH3 & & 0.650 & 0.643 \\
\hline IDBEH2 & & 0.590 & 0.590 \\
\hline IDBEH1 & & -0.098 & Del \\
\hline INSMOT4 & \multirow{4}{*}{ INSMOT } & 0.609 & 0.625 \\
\hline INSMOT3 & & 0.474 & Del \\
\hline INSMOT2 & & 0.517 & 0.538 \\
\hline INSMOT1 & & 0.559 & 0.535 \\
\hline INTSTIM4 & \multirow{4}{*}{ INTSTIM } & 0.487 & Del \\
\hline INTSTIM3 & & 0.793 & 0.821 \\
\hline INTSTIM2 & & 0.542 & 0.509 \\
\hline INTSTIM1 & & 0.499 & Del \\
\hline INDCON4 & \multirow{4}{*}{ INDCON } & 0.769 & 0.774 \\
\hline INDCON3 & & 0.713 & 0.722 \\
\hline INDCON2 & & 0.433 & Del \\
\hline INDCON1 & & 0.423 & Del \\
\hline IDINF4 & \multirow{4}{*}{ IDINF } & 0.619 & 0.617 \\
\hline IDINF3 & & 0.783 & 0.783 \\
\hline IDINF2 & & 0.683 & 0.688 \\
\hline IDINF1 & & 0.715 & 0.711 \\
\hline Cons1 & \multirow{5}{*}{ Cons } & 0.136 & Del \\
\hline Cons2 & & 0.862 & 0.895 \\
\hline Cons3 & & 0.886 & 0.878 \\
\hline Cons4 & & 0.515 & Del \\
\hline Cons5 & & 0.279 & Del \\
\hline Sport1 & \multirow{5}{*}{ Sport } & 0.412 & Del \\
\hline Sport2 & & 0.645 & 0.516 \\
\hline Sport3 & & 0.362 & Del \\
\hline Sport4 & & 0.743 & 0.802 \\
\hline Sport5 & & 0.547 & 0.600 \\
\hline CivVir1 & \multirow{4}{*}{ CivVir } & 0.297 & Del \\
\hline CivVir2 & & 0.933 & 0.923 \\
\hline CivVir3 & & 0.953 & 0.965 \\
\hline CivVir4 & & 0.476 & Del \\
\hline Cour1 & \multirow{5}{*}{ Cour } & 0.461 & Del \\
\hline Cour2 & & 0.533 & Del \\
\hline Cour3 & & 0.554 & Del \\
\hline Cour4 & & 0.636 & 0.532 \\
\hline Cour5 & & 0.702 & 0.840 \\
\hline Altru1 & \multirow{5}{*}{ Altru } & 0.912 & 0.912 \\
\hline Altru2 & & 0.927 & 0.926 \\
\hline Altru3 & & 0.946 & 0.947 \\
\hline Altru4 & & 0.950 & 0.949 \\
\hline Altru5 & & 0.749 & 0.749 \\
\hline CSR Practice1 & \multirow{4}{*}{ CSR Practices } & 0.519 & 0.508 \\
\hline CSR Practice2 & & 0.694 & 0.681 \\
\hline CSR Practice3 & & 0.424 & Del \\
\hline CSR Practice4 & & 0.502 & 0.517 \\
\hline
\end{tabular}


Table 3. The overall assessment of the model fit indices.

\begin{tabular}{cccc}
\hline Fit Index & Recommended Values & Acceptable Values & Source \\
\hline CMIN $\left(\chi^{2}\right)$ & & & \\
$p$-value & $>0.05$ & $\geq 0.000$ & {$[59]$} \\
$\chi^{2} /$ df & $\leq 3.00$ & $\leq 5.00$ & {$[60]$} \\
GFI & $\geq 0.90$ & $\geq 0.80$ & {$[61]$} \\
AGFI & $\geq 0.80$ & $\geq 0.80$ & {$[61]$} \\
CFI & $\geq 0.90$ & $\geq 0.90$ & {$[60]$} \\
TLI & $\geq 0.90$ & $\geq 0.90$ & {$[59]$} \\
IFI & $\geq 0.90$ & $\geq 0.90$ & {$[59,62]$} \\
RMSEA & 0.05 to 0.08 & $\leq 0.10$ & {$[62]$} \\
\hline
\end{tabular}

\subsection{Second-Order Confirmatory Factor Analysis}

Second-order confirmatory factor analysis showed the loadings of the five factors of TLS on their general constructs of TLS, and the loadings of the five factors of OCB on the general factor of OCB, which loaded well onto the second-order TLS, OCB, and CSR general constructs, as shown in Table 4. The second order model fit indices were: Chi-square $=1511.938$. , Chi-square $/ \mathrm{df}=1511.938 / 422=3.583$, $\mathrm{df}=422, \mathrm{GFI}=0.905, \mathrm{AGFI}=0.801, \mathrm{CFI}=0.898, \mathrm{TLI}=0.826, \mathrm{IFI}=0.843, \mathrm{RMSEA}=0.051$.

The overall measures for the hypnotized model fit indices shown in Figure 1 are: Chi-square $=793.867$, Chi-square/df $=1.951, \mathrm{df}=407.000, \mathrm{GFI}=0.886, \mathrm{AGFI}=0.862, \mathrm{CFI}=0.944, \mathrm{TLI}=0.936$, IFI $=0.945$, RMSEA $=0.049$, and these model fit indices of the constructs were all within the acceptable range. These results showed that the hypnotized model for the data had a better fit than did the original model.

Table 4. Standardized regression weights of the general constructs of transformational leadership style(TLS) and organizational citizenship behavior (OCB).

\begin{tabular}{cccc}
\hline Component Factors & & Constructs & Estimate \\
\hline IDINF & $<-$ & TLS & 0.572 \\
IDBEH & $<-$ & TLS & 0.616 \\
INSMOT & $<-$ & TLS & 0.511 \\
INTSTIM & $<-$ & TLS & 0.522 \\
INDCON & $<-$ & TLS & 0.505 \\
Cons & $<-$ & OCB & 0.594 \\
Sport & $<-$ & OCB & 0.578 \\
CivVir & $<-$ & OCB & 0.502 \\
Cour & $<-$ & OCB & 0.501 \\
Altru & $<-$ & OCB & 0.608 \\
\hline
\end{tabular}

\subsection{Effects of TLS, OCB, and CSR Interaction}

Figure 1 shows the model of the study, which presents the mediation of OCB between TLS and CSR practices. The effect with its significance level of TLS on CSR was computed, and the results are shown in Tables 5 and 6. This included the direct effect of TLS on CSR, the indirect effect of TLS-through the mediation of OCB-on CSR, and the total effect of TLS on CSR, which is the sum of the direct and indirect effect of TLS on CSR. In addition to this, the total effect of TLS on OCB and the total effect of OCB on CSR were computed.

Table 5 shows that the standardized total effect of TLS on OCB is 0.309 , and this is the direct effect as well. This means that when TLS goes up by 1 , OCB goes up by 0.309 , and the same can be applied to all effects according to their values. However, the total effect of OCB on CSR is 0.20 , which is the direct effect as well. More importantly, Table 5 shows that the direct effect of TLS on CSR is 0.06 with a significance of 0.041 , and that the indirect effect of OCB on CSR is 0.062 with a significance of 0.000 . Thus the total effect of TLS on CSR is 0.122 . That is, the total effect is both the direct (unmediated) and 
indirect (mediated by OCB) effects of TLS on CSR, which is $(0.309 \times 0.20)+0.062=0.122$. These results are shown in Table 5. All of these results are significant at $p<0.05$ for all of these effects; the direct, the indirect, and the total effects as shown in Table 6.

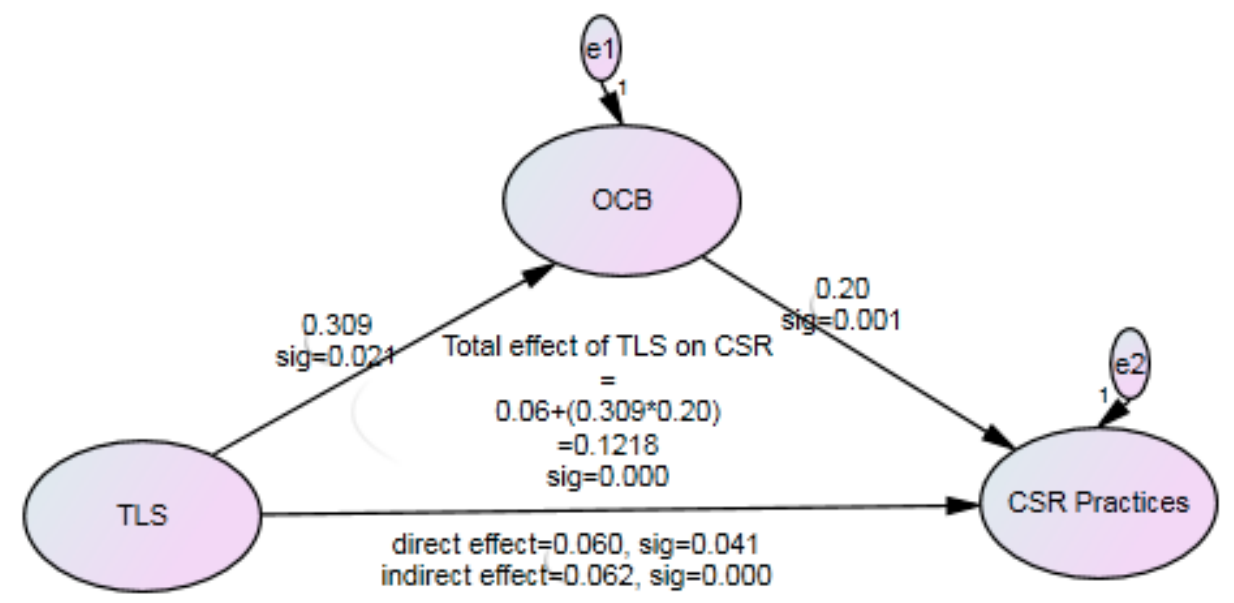

Figure 1. The model of the study showing the mediation of OCB between TLS and CSR practices.

Table 5. Standardized total, direct, and indirect effects.

\begin{tabular}{ccc}
\hline EFFECT & TLS & OCB \\
\hline \multicolumn{3}{c}{ Standardized Total Effects/Sig } \\
OCB & 0.309 & $\ldots$ \\
CSR Practices & 0.122 & 0.20 \\
\hline \multicolumn{3}{c}{ Standardized Direct Effects/Sig } \\
OCB & 0.309 & $\ldots$ \\
CSR Practices & 0.060 & 0.20 \\
\hline \multicolumn{3}{c}{ Standardized Indirect Effects/Sig } \\
OCB & $\ldots .062$ & $\ldots$ \\
CSR Practices & $\ldots$ \\
\hline
\end{tabular}

Table 6. Standardized effects: two-tailed significance.

\begin{tabular}{ccc}
\hline EFFECT & TLS & OCB \\
\hline Standardized Total Effects/Sig & \\
OCB & 0.021 & $\ldots$ \\
CSR Practices & 0.000 & 0.001 \\
Standardized Direct Effects/Sig & \\
OCB & 0.021 & $\ldots$ \\
CSR Practices & 0.041 & 0.001 \\
Standardized Indirect Effects/Sig & \\
OCB & $\ldots$ & $\ldots$ \\
CSR Practices & 0.000 & $\ldots$ \\
\hline
\end{tabular}

\section{Discussion and Conclusions}

In this study, we investigated how transformational leadership style (TLS) indirectly impacts corporate social responsibility (CSR) practices through the mediation of organizational citizenship behavior (OCB). This was done after testing the properties regarding the reliability of the scores and evidence of validity of the internal structure of the measurement instrument. For the first hypothesis, we found that the three instruments needed to be modified, wherein the initial 20 items of the five components of TLS, 24 items of the 5 components of OCB, and the 4 items of the single component of CSR practices were not all accepted. Thus, the hypothesis was reconsidered to include 14 items 
for the 5 components of TLS rather than the original 20 items, and 14 items for the 5 components of OCB rather than the original 24 items, and 3 items for the single component of CSR practices rather than the original 4 items. The re-specified factor loadings were all accepted. In addition, 31 items remaining from the 48 items of TLS, OCB, and CSR practices were shown to be accounted for by the TLS-OCB-CSR practices model, which means that each item loads only onto the TLS or OCB or CSR practices constructs, additionally, the TLS-OCB CSR practices hypothesized model showed a relatively good fit with the sample data. However, with the deletion of the mentioned items, this supports H1.

The results of the SEM support hypothesis H2, in which we anticipated that TLS would have a positive direct effect on employees' CSR practices. More importantly, results support $\mathbf{H} 3$, in which we anticipated that TLS would have a positive indirect effect on employees' CSR practices through the mediation of OCB. TLS appeared to have a total significant effect on CSR practices equal to 0.122 , which is due to both the direct (unmediated) significant effect (equal to 0.060) and the indirect (mediated by OCB's significant effect for TLS on CSR practices; 0.062). These results confirm four major issues. First, they show the direct effect of OCB on CSR practices, which is very important to the indirect effect of TLS on CSR practices, because if this were zero, no mediation would happen at all. Second, they show that there is a significant direct effect for TLS on CSR practices. Third, and most importantly, they show an indirect effect for TLS on CSR practices through the mediation of OCB, and that the magnitude of the indirect effect of TLS on CSR practices through the mediation of OCB is larger than that of the direct effect.

Thus, it is evident from the analysis that TLS in all of its components, as perceived by employees, has significant effects on CSR practices through the mediation of OCB in all of its components. Indeed, this can support the importance of (TLS) and be supported by Yusra et al. [22] who claimed that transformational leadership style is one of the most implemented styles because it has integrity, defined and clear goals, encourages clear steps to communication and being expressive. However, as the direct effect of TLS on CSR is lower in effect and in significance than the indirect effect of TLS on CSR through the mediation of OCB, this means that the impact of TLS on CSR practices can only be better predicted by the mediation of $\mathrm{OCB}$, and of course by computing and adding both the direct and the indirect effect of TLS on CSR together. Eventually, this may lead leaders to highly focus on instilling OCB, should they be willing to achieve and encourage CSR practices on their employees. By so doing, organizations can only achieve their objectives in carrying out their duties while achieving ethical, environmental, and humanitarian purposes. Based on these results, improving CSR practices will lead to achieving sustainability in higher education corporations in Jordan. This is supported by Anderson and Cavanagh and Matten $[1,6]$, who argued that organizational effectiveness and sustainability performance requires $\mathrm{OCB}$, which, once improved, causes CSR practices to improve directly. Nevertheless, one can conclude that OCB and CSR practices are integrated in addressing many of the sustainability issues, as OCB builds capability and values in an organization to face endogenous threats, and CSR practices build capability and values to face exogenous threats, both meeting multiple stakeholders' needs and demands. This is supported by the fact that building a sustainable world requires consideration of the intersection of leadership and ethics.

\subsection{Implications}

This study has several practical implications. First, we found a positive indirect effect of the transformational leadership style on corporate social responsibility through the mediation of the organizational citizenship behavior. This result could help leaders to perceive the advantages of being part of ethically imposed corporate social responsibility practices. Moreover, as supported by Dhiman [3], leaders could become more aware in reconsidering and associating business with ethical, philanthropic, and environmental issues, and in shaping their organizations and being aware that this requires them to act as a model for employees of being engaged in corporate social responsibility practices. Hence, organizations should pay more attention to their leadership styles, and ensure it instills the organizational citizenship behavior to achieve corporate social responsibility practices 
for the good of sustainability that would reflect positively to stakeholders, employees, customers, suppliers, and the community, leading to long-term business success. Moreover, this study will assist future researchers with further examining the relationship between the transformational leadership style, corporate social responsibility and the organizational citizenship behavior.

\subsection{Contributions}

This research contributes to this field by providing a validated model in the Jordanian context, that is capable of measuring TLS, OCB, and CSR practices and their impact on each other, especially the indirect effect of TLS on CSR practices through the mediation of OCB. In addition, this research contributes to the literature on TLS-OCB-CSR practices by increasing academic knowledge concerning the mediation of OCB between TLS and CSR practices; no research has so far been conducted on this mediation topic, giving this research its value and originality. This means that researchers, in their future studies in this field, will now be aware of the probable missing link between leadership style and CSR practices.

\subsection{Limitations}

It is possible that the findings are unique to any of the demographic variables which have not been checked. For example, this study showed that males dominated females with a $241(61.5 \%) / 151$ $(38.5 \%)$ ratio. Therefore, future studies are needed to consider such limitations. This is in addition to considering moderator or mediating variables, such as demographic variables, in achieving better CSR practices.

Author Contributions: Supervision, T.A.; Writing—original draft, K.A. All authors have read and agreed to the published version of the manuscript.

Funding: This research received no external funding.

Conflicts of Interest: The authors declare no conflict of interest.

\section{Appendix A. (TLS) Items}

1. Idealized Influence

II1 (Instills pride in me for being associated with him/her.)

II2 (Goes beyond self-interest for the good of the group.)

II3 (Acts in a way that builds my respect.)

II4 (Displays a sense of power and confidence.)

2. Idealized Behavior

IB1 (Talks about their most important values and beliefs.)

IB2 (Specifies the importance of having a strong sense of purpose.)

IB3 (Considers the moral and ethical consequences of decisions.)

IB4 (Emphasizes the importance of having a collective sense of mission.)

3. Inspirational Motivation

IM1 (Talks optimistically about the future.)

IM2 (Talks enthusiastically about what needs to be accomplished.)

IM3 (Articulates a compelling vision of the future.)

IM4 (Expresses confidence that goals will be achieved.)

4. Intellectual Stimulation

IS1 (Re-examines critical assumptions to question whether they are appropriate.)

IS2 (Seeks differing perspectives when solving problems.)

IS3 (Gets me to look at problems from many different angles.)

IS4 (Suggests new ways of looking at how to complete assignment.)

5. Individual Consideration

IC1 (Spends time teaching and coaching.) 
IC2 (Treats me as an individual rather than just as a member of the group.)

IC3 (Considers me as having different needs, abilities, and aspirations from others.)

IC4 (Helps me to develop my strengths.)

\section{Appendix B. (OCB) Items}

\section{Conscientiousness}

Cons 1 (I believe in giving an honest day's work for an honest day's pay.)

Cons 2 (My attendance at work is above the norm.)

Cons 3 (I don't take extra breaks.)

Cons 4 (Obeys organization rules and regulations even when no one watching.)

Cons 5 (I am one of most conscientious employees.)

\section{Sportsmanship (reverse questions)}

Sport 1 (I am the classic "squeaky wheel" who always needs greasing.)

Sport 2 (I consume a lot of time complaining about trivial matters.)

Sport 3 (I tend to make "mountains out of molehills".)

Sport 4 (I always focus on what's wrong, rather than the positive side.)

Sport 5 (I always find fault with what the organization is doing.)

\section{Civic Virtue}

CivVir 1 (I keep abreast of changes in the organization.)

CivVir 2 (I attend meetings that are not mandatory, but are considered important.)

CivVir 3 (I attend functions that are not required, but help the organization image.)

CivVir 4 (I read and keep up with organization announcements, memos, and so on.)

\section{Courtesy}

Cour 1 (I try to avoid creating problems for coworkers.)

Cour 2 (I consider the impact of my actions on coworkers.)

Cour 3 (I don't abuse the rights of others.)

Cour 4 (I take steps to try to prevent problems with other workers.)

Cour 5 (I am mindful of how my behavior affects other people's jobs.)

\section{Altruism}

Altru 1 (I help others who have heavy workloads.)

Altru 2 (I am always ready to lend a helping hand to those around me.)

Altru 3 (I help others who have been absent.)

Altru 4 (I willingly help others who have work related problems.)

Altru 5 (I help orient new people even though it is not required.)

\section{Appendix C. (CSR) Practices Items}

CSR Practice1 Our company conducts many environmental (CSR) practices

CSR Practice2 Our company conducts many ethical (CSR) practices

CSR Practice3 Our company conducts many philanthropic (CSR) practices

CSR Practice4 Our company conducts many stakeholder-relation (CSR) practices

\section{References}

1. Anderson, S.; Cavanagh, J. Top 200: The Rise of Corporate Global Power; Institute of Policy Studies: Washington, DC, USA, 2000.

2. Ogbonna, E.; Harris, C. Leadership style, organizational culture and performance: Empirical evidence from UK companies. Int. J. Hum. Resour. Manag. 2000, 11, 766-788. [CrossRef]

3. Dhiman, D. The Link between Organizational Citizenship Behavior (OCB) and Sustainability; Allied Telesis, Inc.: San Jose, CA, USA, 2010.

4. Dutton, J.; Dukerich, J.; Harquail, C. Organizational images and member identification. Adm. Sci. Q. 1994, 39, 239-263. [CrossRef] 
5. Sachs, J.D. The Age of Sustainable Development; Columbia University Press: New York, NY, USA, 2015; p. 3.

6. Matten, M.J. Government as a Driver of Corporate Social Responsibility. In Dirk, International Centre for Corporate Social Responsibility; No. 20-2004 ICCSR Research Paper Series; ICCSR: New Delhi, India, 2004; p. 2.

7. Knowles, R.N. Self-Organising Leadership: Transparency and Trust. In Management Models for Corporate Social Responsibility; Jonker, J., de Witte, M., Eds.; Springer: Berlin/Heidelberg, Germany, 2006; pp. 134-139.

8. Andrew, M.L. Corporate Social Responsibility Reporting through the Lens of ISO 26000: A Case of Malawian Quoted Companies. Int. Bus. Res. 2015, 8, 28-41.

9. Shephard, K.; Guiney, B. Researching the professional-development needs of community-engaged scholars in a New Zealand university. Sustainability 2017, 9, 1249. [CrossRef]

10. Nejati, M.; Shafaei, A.; Salamzadeh, Y.; Daraei, M. Corporate social responsibility and universities: A study of top 10 world universities' websites. Afr. J. Bus. Manag. 2011, 5, 440-447.

11. Buffington, J.; Hart, S.; Milstein, M. Tandus 2010; Race to Sustainability; Center for Sustainable Enterprise, University of North Carolina: Chapel Hill, NC, USA, 2002.

12. Haden, S.; Oyler, P.H.J. Historical, practical and theoretical perspectives on green management: An exploratory analysis. Manag. Decis. 2009, 47, 1041-1055. [CrossRef]

13. Jabbour, C. Greening of business schools: A systemic view. Int. J. Sustain. High. Educ. 2010, 11, 49-60. [CrossRef]

14. Alshuwaikhat, H.M.; Abubakar, I. An integrated approach to achieving campus sustainability: Assessment of the current campus environmental management practices. J. Clean. Prod. 2008, 16, 1777-1785. [CrossRef]

15. Deegan, C. The legitimising effect of social and environmental disclosures-A theoretical foundation. Account. Audit. Account. J. 2002, 15, 282-311. [CrossRef]

16. Leal, F. Dealing with misconceptions on the concept of sustainability. Int. J. Sustain. High. Educ. 2000, 1, 9-19. [CrossRef]

17. Robinson, S.; Morrison, E. Psychological contracts and (OCB): The effect of unfulfilled obligations. J. Organ. Behav. 1995, 16, 289-298. [CrossRef]

18. Mohe.org; The Ministry of Higher Education: Amman, Jordan, 2018.

19. Allmer, T. Theorising and Analysing Academic Labour. TripleC 2018, 16, 49-77. [CrossRef]

20. Bass, B.; Avolio, B.J. Developing transformational leadership: 1992 and beyond. J. Eur. Ind. Train. 1990, 14, 21-27. [CrossRef]

21. Goleman, D.; Boyatzis, R.; Mckee, A. The New Leaders. Transforming the Art of Leadership into the Science of Results; Little, Brown: London, UK, 2002.

22. Yusra, K.; Sana, A. Leadership Styles \& Using Appropriate Styles in Different Circumstances. Researchgate 2016. Available online: https://www.researchgate.net/publication/323797001_Leadership_Styles_Using Appropriate_Styles_in_Different_Circumstances (accessed on 21 May 2020).

23. Pillai, R.; Schriesheim, C.; Williams, E. Fairness perceptions and trust as mediators for transformational and transactional leadership: A two-sample study. J. Manag. 1999, 25, 897-933. [CrossRef]

24. Wagude, J.; Charles, R.; Anne, N. Influence of Idealized Behaviour On the Implementation of Cdf Construction Projects in Public Secondary Schools in Kisumu County, Kenya. Eur. Sci. J. 2015, 11, 255-273.

25. Castillo, I.; Adell, F.L.; Alvarez, O. Relationships between personal values and leadership behaviors in basketball coaches. Front. Psychol. 2018, 9, 1661. [CrossRef]

26. Randolph, B.; Smith, B.; Slobodnikova, A. Visual Images of People at Work: Influences on Organizational Citizenship Behavior. In Visual Ethics Research in Ethical Issues in Organizations; Schwartz, M., Harris, H., Comer, D., Eds.; Emerald Publishing Limited: Bingley, UK, 2018.

27. Cohen, E.V. Do good citizens make good organizational citizens? An empirical examination of the relationship between general citizenship and organizational citizenship behavior in Israel. Adm. Soc. 2000, 32, 596-624. [CrossRef]

28. Igor, K.; Daniel, H.; Mari, B. Predicting organizational citizenship behavior: The role of work-related self. Sage Open 2019, 9. [CrossRef]

29. Khan, S.; MohdZabid, A. The mediating effect of organizational commitment in the organizational culture, leadership and organizational justice relationship with organizational citizenship behavior: A study of academicians in private higher learning institutions in Malaysia. Int. J. Bus. Soc. Sci. 2012, 3, 83-91. 
30. Ozyilmaz, A.; Erdogan, B.; Karaeminogullari, A. Trust in organization as a moderator of the relationship between self-efficacy and workplace outcomes: A social cognitive theory-based examination. J. Occup. Organ. Psychol. 2018, 91, 181-204. [CrossRef]

31. Smith, C.A.; Organ, D.W.; Near, J.P. Organizational citizenship behavior: Its nature and antecedents. J. Appl. Psychol. 1983, 68, 653-663. [CrossRef]

32. Yildiz, $\mathrm{H}$. The interactive effect of positive psychological capital and organizational trust on organizational citizenship behavior. Sage Open 2019, 9. [CrossRef]

33. Akinbode, G.A. Personality Characteristics as Predictors of Organizational Citizenship Behavior (OCB). Master's Thesis, Department of Psychology, Unilag, Lagos, Nigeria, 2010. Unpublished.

34. Okediji, A.A.; Esin, P.; Sanni, K.B.; Umoh, O.O. The influence of personality characteristics and gender on organizational citizenship behavior. Glob. J. Soc. Sci. 2009, 8, 69-76.

35. Kim, H. The roles of tacit knowledge and (OCB) in the relationship between group-based pay and firm performance. J. Technol. Hum. Resour. Manag. 2009, 9, 120-139. [CrossRef]

36. Broucek, W. An examination of organizational citizenship behavior in an academic setting from the perspective of the five factor model. J. Int. Bus. Econ. Res. 2003, 2, 63-69. [CrossRef]

37. Nusair, N.; Ababneh, R.; Kyung Bae, Y. The impact of (TLS) on innovation as perceived by public employees in Jordan. Int. J. Commer. Manag. 2012, 22, 182-201. [CrossRef]

38. Tareq, G. The impact of (TLS) on organizational performance: Evidence from Jordan. Int. J. Hum. Res. Stud. 2016, 6. [CrossRef]

39. Akif, L.; Sahar, M. The impact of leadership styles used by the academic staff in the Jordanian public universities on modifying students' behavior: A field study in the northern region of Jordan. Int. J. Bus. Manag. 2013, 8. [CrossRef]

40. Alsheikh, G.; Sobihah, M. Effect of behavioral variables on organizational citizenship behavior (OCB), with job satisfaction as moderating among Jordanian five-star hotels: A pilot study. Int. J. Ethics Syst. 2019, 35, 272-283. [CrossRef]

41. Abd, E.; Cohen, A. The role of values and leadership style in developing (OCB) among Arab teachers in Israel. Leadersh. Organ. Dev. J. 2015, 36, 308-327.

42. Oo, E.; Jung, H.; Park, I.-J. Psychological Factors Linking Perceived CSR to OCB: The Role of Organizational Pride, Collectivism, and Person-Organization Fit. Sustainability 2018, 10, 2481. [CrossRef]

43. Cingöz, A.; Akdogan, A. A Study on Determining the Relationships among Corporate Social Responsibility, Organizational Citizenship Behavior, and Ethical Leadership. Int. J. Innov. Technol. Manag. 2018, 16, 1940004. [CrossRef]

44. Gao, Y.; He, W. Corporate social responsibility and employee organizational citizenship behavior: The pivotal roles of ethical leadership and organizational justice. Manag. Decis. 2017, 55, 294-309. [CrossRef]

45. Wang, X. Corporate Social Responsibility and Collective OCB: A Social Identification Perspective. Front. Psychol. 2019, 10, 2720. [CrossRef] [PubMed]

46. Mohammad, H.; Nik, R. The Implementation of Corporate Social Responsibility (CSR) Programs and its Impact on Employee Organizational Citizenship Behavior. Int. J. Bus. Commer. 2012, 2, 67-75.

47. Ong, M.; Mayer, D.; Leigh, P.T.; Wellman, N. When corporate social responsibility motivates employee citizenship behavior: The sensitizing role of task significance. Organizational Behavior and Human Decision Processes. Res. Collect. Lee Kong Chian Sch. Bus. 2018, 144, 44-59.

48. Iqbal, S.; Farid, T.; Ma, J.; Khattak, A.; Nurunnabi, M. The Impact of Authentic Leadership on Organizational Citizenship Behaviours and the Mediating Role of Corporate Social Responsibility in the Banking Sector of Pakistan. Sustainability 2018, 10, 2170. [CrossRef]

49. Mazutis, D. CEO open executive orientation and positive CSR initiative adoption. In Academy of Management Proceedings; Academy of Management: Briarcliff Manor, NY, USA, 2014.

50. Kim, M.-S.; Thapa, B. Relationship of Ethical Leadership, Corporate Social Responsibility and Organizational Performance. Sustainability 2018, 10, 447.

51. Walumbwa, F.; Avolio, B.; Gardner, W.; Wernsing, T.; Peterson, S. Authentic leadership: Development and validation of a theory-based measure. J. Manag. 2008, 34, 89-126. [CrossRef]

52. Walumbwa, F.O.; Wang, P.; Wang, H.; Schaubroeck, J.; Avolio, B.J. Retracted: Psychological Processes Linking Authentic Leadership to Follower Behaviors. Leadersh. Q. 2010, 21, 901-914. [CrossRef] 
53. Shapira-Lishchinsky, O.; Tsemach, S. Psychological Empowerment as a Mediator Between Teachers' Perceptions of Authentic Leadership and Their Withdrawal and Citizenship Behaviors. Educ. Adm. Q. 2014, 50, 675-712. [CrossRef]

54. Edú, V.; Moriano, J.; Molero, A.; Topa, C. Authentic leadership and its effect on employees' organizational citizenship behaviours. Psicothema 2012, 24, 561-566.

55. Bass, B.; Avolio, B. Multifactor Leadership Questionnaire. Manual and Sampler Set, 3rd ed.; Mind Garden Inc.: Redwood City, CA, USA, 2004.

56. Podsakoff, P.; MacKenzie, S.; Paine, J.; Bachrach, D. Organizational citizen ship behaviors: A critical review of the theoretical and empirical literature and suggestions for future research. J. Manag. 2000, 26, 513-563.

57. Bollen, K.A. Structural Equations with Latent Variables; Wiley: New York, NY, USA, 1989.

58. Byrne, B.M. Structural Equation Modeling with AMOS: Basic Concepts, Applications and Programming; Routledge: London, UK, 2012.

59. Hair, J.F.; Black, W.C.; Babin, B.J.; Anderson, R.E.; Tatham, R.L. Multivariate Data Analysis, 6th ed.; Prentice Hall: Upper Saddle River, NJ, USA, 2006.

60. Bagozzi, R.; Yi, Y.; Singh, S. On the use of structural equation models in experimental designs: Two extensions. Int. J. Res. Mark. 1991, 8, 125-140. [CrossRef]

61. Hoyle, R.H.; Kenny, D.A. Statistical Strategies for Small Sample Research; Sage: Thousand Oaks, CA, USA, 1999.

62. Aksu-Dunya, B.; Karakaya-Ozyer, K. A review of structural equation modeling applications in Turkish educational science literature, 2010-2015. Int. J. Res. Educ. Sci. 2018, 4, 279-291.

(C) 2020 by the authors. Licensee MDPI, Basel, Switzerland. This article is an open access article distributed under the terms and conditions of the Creative Commons Attribution (CC BY) license (http://creativecommons.org/licenses/by/4.0/). 